\title{
Diagnóstico da gestão do conhecimento: um estudo em uma organização da sociedade civil de interesse público
}

\section{Knowledge management diagnosis: a study in a civil society organization of public interest}

\author{
Ismael de Mendonça Azevedo ${ }^{1}$ \\ Lydia Maria Pinto Brito ${ }^{2}$ \\ Manoel Pereira da Rocha Neto ${ }^{3}$ \\ Maria Valéria Pereira Araújo ${ }^{4}$
}

\section{Resumo}

As organizações mudaram a sua forma de gerar e gerir riqueza a partir da gestão do conhecimento. Neste contexto este estudo parte da seguinte questão: qual o nível atual da gestão do conhecimento na percepção dos coordenadores de unidades do Instituto Nordeste Cidadania? O seu objetivo geral foi: diagnosticar o nível atual da gestão do conhecimento de uma Organização da Sociedade Civil de Interesse Público - OSCIP, a partir da percepção dos coordenadores de unidades no Rio Grande do Norte, mediante aplicação do Diagnóstico de Gestão do Conhecimento de Bukowitz e Williams. O estudo foi elaborado com base em textos de referência. Trata-se de um estudo de caso qualitativo e descritivo. Os resultados revelam que, o instituto encontra-se em um elevado nível de gestão do conhecimento nos processos táticos e estratégicos. Conclui-se, porém, que precisa trabalhar pontualmente alguns indicadores para refinar o processo de gerenciamento do conhecimento.

Palavras-chaves: Diagnóstico da gestão do conhecimento. Gestão do conhecimento. Terceiro Setor.

\begin{abstract}
Organizations have changed their way of generating and managing wealth from knowledge management. In this context, this study is based on the following question: what is the current level of knowledge management in the perception of coordinators of units of the Instituto Nordeste Cidadania? The general objective was to diagnose the current level of knowledge management of a Civil Society Organization of Public Interest (OSCIP), based on the perception of the coordinators of units in Rio Grande do Norte, through the application of Bukowitz Knowledge Management Diagnostics and Williams. The study was based on reference texts. It is a qualitative and descriptive case study. The results show that the institute is at a high level of knowledge management in tactical and strategic processes. It is
\end{abstract}

\footnotetext{
${ }^{1}$ Mestre em Administração, Docente na Universidade Potiguar (UnP).

2 Doutora em Educação, Docente no Programa de Pós-Graduação em Administração da UnP.

${ }^{3}$ Doutor em Educação, Docente no Programa de Pós-Graduação em Administração da UnP.

${ }^{4}$ Doutora em Administração, Docente no Programa de Pós-Graduação em Administração da Universidade Federal do Rio Grande do Norte (UFRN).
} 
concluded, however, that it needs to work punctually some indicators to refine the process of knowledge management.

Keywords: Knowledge management. Knowledge management diagnostics. Third sector.

\section{Introdução}

A gestão das organizações, até a década de 1980, tinha entre os seus principais fatores o acesso à mão de obra barata, aos recursos naturais e ao capital financeiro (Freire, Ueno, Dias \& Santos, 2013). Pouca importância era atribuída a informação e ao conhecimento quanto parte do ativo, uma forma de capital ou até um bem organizacional (Cardoso, 2007). Esta década foi primordial para que as empresas de maneira geral percebessem que a informação era o recurso mais crítico que elas poderiam ter e que só com a expansão do acesso e o aumento da qualidade deste, é que poderia haver a melhora do desempenho nos negócios, além da ampliação dos ativos (Davenport, Eccles \& Prusak, 1992; Bukowitz, Williams \& Mactas, 2004).

Foi apenas no final desta mesma década e durante a década posterior, que as características de gestão se desenvolvem para outras temáticas que ainda se destacam hoje, dentre elas, a gestão do conhecimento (Freire et al., 2013).

Desde a década de 1990, as pesquisas na área de gestão estão relacionadas ao gerenciamento de processos que tornam o conhecimento organizacional um elemento gerador de valor (Nonaka, 1994; Freire et al., 2013; Davenport, 2015). O conhecimento se constituiu como um recurso valioso e, de certo modo, insubstituível enquanto força motriz para as empresas que atuam em contextos incertos e imprevisíveis (Cardoso, 2007). Ou seja, para as organizações atuais, o verdadeiro diferencial competitivo se concentra na gestão do conhecimento (Freire et al., 2013).

A Gestão do Conhecimento pode ser compreendida como uma disciplina que visa a projeção do conhecimento a partir da implementação de um sistema ou métodos, com o objetivo de identificar identificar, captar e compartilhar sistematicamente o conhecimento contido em uma organização, e desse modo converter o conhecimento em valor para a organização (Tarapanoff, 2006; Nonaka \& Toyama, 2003; Davenport \& Prusak, 2003; Takeuchi \& Nonaka, 2008).

É dentro deste novo contexto técnico, socioeconômico e cultural, que encontramos novas formas de pensar quanto aos insumos na condição de ativos intangíveis, ou capital intelectual, dentro das empresas (Guerrero-Baena, Gómez-Limón \& Fruet Cardozo, 2013). 
É possível destacar então, que dois destes insumos adquiriram especial importância para o aumento da capacidade de inovação e aumento da competitividade: a informação e o conhecimento (Takeuchi \& Nonaka, 2008; Strauhs et al., 2012). De certo, é a partir dos pressupostos culturais das organizações (Schein, 2004) que se idealiza o núcleo para as regras e métodos (Trompenaars, 1996) do gerenciamento com foco na gestão do conhecimento de modo à provocar inovação, competitividade e sustentabilidade organizacional ao longo do tempo.

Uma cultura voltada para a gestão do conhecimento é capaz de encorajar e melhorar a colaboração entre os funcionários a ponto de tornar-se a empresa um ambiente fluído em conhecimento e desenvolvimento de inovações, já que a inovação depende da forma de como o conhecimento é criado e compartilhado (Deng, 2006; An, Deng, Chao \& Bai, 2014; Gupta, Massa \& Azzopardi, 2016). Assim, é necessário criar um ambiente no qual todo trabalhador veja o gerenciamento do conhecimento como parte do seu trabalho (Davenport \& Grover, 2001), pois todos eles têm um propósito em comum nas mãos (Turner, Zimmerman \& Allen, 2012) que são os objetivos organizacionais.

O modelo utilizado na pesquisa é o Diagnóstico da Gestão do Conhecimento (DCG) de Bukowitz e Williams (2002) que compreende dois processos: o tático e o estratégico. O processo tático compreende os processos: obtenha, use, aprenda e contribua (Dalkir, 2011). Nesses quatro processos sequenciais, as pessoas reúnem a informação de que necessitam para o seu trabalho diário, e a partir disso "utilizam o conhecimento para gerar valor", dessa forma "aprendem com o que criaram e transmitem esse conhecimento para o sistema", para que outras pessoas utilizem quando necessário na resolução dos seus próprios problemas (Bukowitz \& Williams, 2002, p. 25).

O processo estratégico reúne processos que se organizam ao alinhamento da estratégia de conhecimento da organização com estratégia geral da organização. Nesse processo a organização necessita de "uma avaliação contínua do capital intelectual além de uma comparação com necessidades futuras". O processo estratégico está mais voltado para a análise do papel dos grupos e lideranças organizacionais específicas. No que se refere à liderança, não se tenha a liderança comum, mas "uma liderança que seja parceira da gerência intermediária e da linha de frente”. Por fim, compreende os processos avalie, construa e mantenha e, descarte (Bukowitz \& Williams, 2002, p. 26).

Por fim, é imprescindível que a organização compreenda como o valor é criado, para que o conhecimento valoroso fique armazenado em sua estrutura, ao tempo que se algo pode ser descartado, que seja, como forma de manter a rentabilidade, praticidade, e agilidade. 
Dessa forma, fazer experiências com o conhecimento que detém é uma maneira de reconhecer o que realmente precisa ser mantido para enfrentar o futuro e as incertezas que são inerentes a este. Ao tempo que abster-se de absorver conhecimento inadequado.

\section{Procedimentos Metodológicos}

A pesquisa de natureza qualitativa, caracteriza-se: descritiva - quanto aos fins, (Lakatos, 2003) e estudo de caso - quanto aos procedimentos (Godoy, 1995).

A aplicação dos formulários foi virtual após contatos pessoais e telefônicos com os potenciais respondentes. A pesquisa foi enviada para todos os coordenadores que estavam na ativa durante o mês de maio de 2018, respeitando o direito à liberdade de expressão e livre arbítrio quanto ao envio das respostas. Do total de 37 (trinta e sete) formulários enviados por e-mail para as unidades atuantes no Rio Grande do Norte, obtivemos 21 (vinte e um) respondentes, aproximadamente $57 \%$ dos coordenadores na ativa. Os respondentes caracterizam-se de um modo geral como: sexo masculino, casados, com faixa etária predominante de 30 a 35 anos de idade, com formação superior e com tempo de 2 anos na função, gestores na função de coordenação de equipes com média de 10 funcionários sob seu gerenciamento direto.

O instrumento utilizado para a realização da coleta de dados foi composto de 2 partes: a) um segmento estruturado; e b) um segmento de questões abertas.

O segmento estruturado - Diagnóstico da Gestão do Conhecimento (DGC), foi desenvolvido e validado por Bukowitz e Williams (2002). Ele é dividido em dois processos: tático, que é subdividido em 04 (quatro) seções: Obtenha, Utilize, Aprenda, Contribua e processo estratégico que está subdividido em 03 (três) seções: Avalie, Construa/Mantenha e Descarte. Compondo cada seção temos 20 afirmações, um total de 140 afirmações.

Para apreciação dos resultados por seção, a operacionalização do instrumento se deu seguindo as orientações das autoras, que sugerem a adoção de uma escala de pontuação a ser utilizada no questionário que varia de 1 (um) a 3 (três), sendo 1 (um) equivalente a percepção dos respondentes para a um fator fraco (Frs), 2 (dois) equivalente a um fator de percepção moderado $(\mathrm{M})$ e 3 (três) refere-se a uma descrição de fator forte $(\mathrm{F})$. A pontuação média adotada como padrão aceitável para cada seção é de 30 a 70\%, já que essas são as médias encontradas nos estudos que as autoras realizaram, e para todas as seções no somatório geral é de 55\% (Bukowitz \& Williams, 2002). 
Seguindo uma proposta de análise mais criteriosa e que visa possibilitar o aprofundamento dos resultados obtidos em cada seção do DGC, foi seguido Castro (2011) que atribui uma organização dos itens das sete sessões em Indicadores de Gestão do Conhecimento, conforme a tabela 1 a seguir.

Tabela 1.

Indicadores de Gestão do Conhecimento

\begin{tabular}{|c|c|c|c|c|c|c|c|}
\hline \multirow{2}{*}{$\begin{array}{c}\text { Itens Avaliativos } \\
\text { Específicos } \\
\text { (Indicadores da gestão } \\
\text { do conhecimento) }\end{array}$} & \multicolumn{7}{|c|}{ Domínio Cognitivo (Seções do diagnóstico de gestão do conhecimento) } \\
\hline & Obter & Utilizar & Aprender & Contribuir & Avaliar & $\begin{array}{l}\text { Construir/ } \\
\text { Manter }\end{array}$ & Descartar \\
\hline $\begin{array}{l}\text { Processos, } \\
\text { contextualização, } \\
\text { política de gestão do } \\
\text { conhecimento }\end{array}$ & & & $\begin{array}{c}1,10,12,1 \\
5\end{array}$ & $\begin{array}{c}2,12,15,16 \\
18\end{array}$ & $\begin{array}{c}3,4,9,1 \\
0,13,14 \\
15,17 \\
18,20\end{array}$ & $1,7,16,18$ & $\begin{array}{c}1,2,6,7,10 \\
13,16,17,2 \\
0\end{array}$ \\
\hline $\begin{array}{l}\text { Compartilhamento do } \\
\text { conhecimento, } \\
\text { comunicação, } \\
\text { relacionamento }\end{array}$ & $\begin{array}{c}1,2,4 \\
8,9\end{array}$ & $\begin{array}{l}1,5,8,1 \\
5,18,19\end{array}$ & 19 & $\begin{array}{c}5,7,8,10,11 \\
, 12,13,14,1 \\
6,17,18,19 \\
20\end{array}$ & 2,12 & $1,2,19$ & $2,4,9,19$ \\
\hline $\begin{array}{l}\text { Capacidade de } \\
\text { realização da tarefa }\end{array}$ & 15 & & & & & & \\
\hline $\begin{array}{l}\text { Papeis de gestão do } \\
\text { conhecimento }\end{array}$ & $\begin{array}{l}3,6,1 \\
0,12 \\
13,18\end{array}$ & & & $1,9,16$ & 14 & 3,10 & 6 \\
\hline $\begin{array}{c}\text { Estrutura física e } \\
\text { organizacional }\end{array}$ & & $\begin{array}{c}2,3,11 \\
13,17\end{array}$ & & $4,8,10$ & & & \\
\hline $\begin{array}{l}\text { Meios eletrônicos e } \\
\text { tecnologias da } \\
\text { informação }\end{array}$ & $\begin{array}{l}5,7,1 \\
1,14 \\
16,17\end{array}$ & & & 4,10 & & $\begin{array}{c}2,5,7,11,13 \\
, 17\end{array}$ & \\
\hline $\begin{array}{c}\text { Documentação, } \\
\text { resultados, } \\
\text { mensuração, protocolos } \\
\text { e/ou regras }\end{array}$ & 19,20 & 14 & & & $\begin{array}{c}3,4,5,6 \\
7,8,11 \\
12,17,2 \\
0\end{array}$ & 15,20 & \\
\hline Processo decisório & & 4 & $\begin{array}{c}2,6,8,17 \\
18,20\end{array}$ & & 13 & & $\begin{array}{c}1,3,8,13,14 \\
, 15\end{array}$ \\
\hline $\begin{array}{l}\text { Simulação, jogos, } \\
\text { inovação ou resolução } \\
\text { de problemas }\end{array}$ & & $\begin{array}{c}6,8,9,1 \\
2,20\end{array}$ & $\begin{array}{c}4,11,13,1 \\
6,20\end{array}$ & & & $4,10,14$ & 18 \\
\hline Parceria & & $7,10,16$ & 3,9 & 6 & & $8,12,18$ & $11,12,19$ \\
\hline $\begin{array}{l}\text { Avaliação do } \\
\text { conhecimento }\end{array}$ & & & $5,7,9,14$ & & & & $5,13,16$ \\
\hline Valores & & & & & & 6,9 & \\
\hline $\begin{array}{c}\text { Reconhecimento e } \\
\text { valorização da gestão }\end{array}$ & & & & $3,17,18$ & $1,16,19$ & & 10,20 \\
\hline
\end{tabular}


do conhecimento

Fonte: Castro (2011, p. 79).

Para cada domínio cognitivo foram definidos itens avaliativos específicos (Indicadores de Gestão do Conhecimento) elaborados a partir de vasta pesquisa na literatura sobre Gestão do Conhecimento e transformados em uma escala adequada de valores utilizada para análise e mensuração (Castro, 2011).

Mediante a obtenção dos instrumentos de pesquisa enviados pelos pesquisados e, conferidos quanto ao total preenchimento, bem como, observação dos resultados obtidos, os dados do questionário foram tabulados utilizando-se de planilhas eletrônicas no programa Microsoft Excel 2010, com o cruzamento dos dados, direta e transversalmente, para atender as variáveis de interesse apresentadas em tabelas de frequência das respostas e média percentual.

As questões abertas, foram colocadas para contribuir na melhor compreensão quanto ao conhecimento dos respondentes sobre a temática a partir das seguintes questões: Como você define Gestão do Conhecimento? Qual tipo de conhecimento você passa ou trabalha com seu cliente? Como você percebe que a Gestão do Conhecimento que sua organização tem pode influenciar no desenvolvimento do Nordeste?

Para apuração e analise dos conteúdos escritos pelos coordenadores em formulário de pesquisa, fez-se uso do programa QSR Nvivo10. Considerando que a análise de conteúdo é baseada na palavra como indicador da unidade de análise e tem relação direta com o "número de vezes em que a palavra ocorre" (Bardin, 2002, p. 143) utilizou-se uma análise de conteúdo sem o desenvolvimento da categorização prévia, portanto se criou apenas "as operações de enumeração e tratamento estatístico" reforçando a palavra como unidade de significação (Bardin, 2002, p. 145) para que o software Nvivo 10 pudesse analisar frequências de palavras, correlação de conteúdos e demais análises necessárias.

\section{Discussão e Análise dos Resultados}

\subsection{Diagnóstico da Gestão do Conhecimento}

Após aplicação dos instrumentos, foi possível efetuar a análise das ocorrências de respostas a partir do DGC. Os resultados estão apresentados na Tabela 2 abaixo. Para analisar 
os resultados gerais do diagnóstico mediante tratamento e apuração das respostas dos coordenadores de unidades, utilizou-se de planilhas elaboradas no Microsoft Excel 2010.

Tabela 2.

Resultado geral das pontuações por seção e desempenho

\begin{tabular}{lcccc}
\hline Processo & Seção & Pontos & \% por Seção & Desempenho \\
\hline \multirow{2}{*}{ Tático } & Obter & 48,14 & 80,24 & \\
& Utilizar & 48,71 & 81,19 & \\
& Aprender & 48,95 & 81,59 & Melhor \\
& Contribuir & 48,10 & 80,16 & Pior \\
& Subtotal & $\mathbf{1 9 3 , 9 0}$ & $\mathbf{8 0 , 7 9}$ & \\
Estratégico & Avaliar & 46,43 & 77,38 & Melhor \\
& Construir/Manter & 47,86 & 79,76 & Pior \\
& Descartar & 44,57 & 74,29 & \\
SGC & Subtotal & $\mathbf{1 3 8 , 8 6}$ & $\mathbf{7 7 , 1 4}$ & \\
& Total Geral & $\mathbf{3 3 2 , 7 6}$ & $\mathbf{7 9 , 2 3}$ & \\
\hline
\end{tabular}

Fonte: Dados da pesquisa (2018).

Após apuração e estratificação dos resultados, é possível observar que em todas as seções os resultados encontrados são superiores as médias dos resultados encontrados em outros estudos, pois segundo Bukowitz e Williams (2002) as empresas que aplicaram o questionário tiveram em média pontuações que variaram entre 30 e $70 \%$ em cada seção, e a média geral do diagnóstico ficou em 55\%. Pode-se dizer, então, que os resultados encontrados junto ao Instituto pesquisado são atípicos, pois estão acima de todas as médias por seção e da média total geral.

É válido destacar de maneira distinta cada processo. Desse modo o processo tático, apresentou pontuação geral de 193,90 pontos ou $80,79 \%$ da pontuação total possível de 240 pontos. Isso implica considerar que na percepção dos coordenadores de unidades, na organização a obtenção do conhecimento, assim como a utilização, a aprendizagem e a contribuição ou entrega de conhecimento é algo evidente, ou que está presente na rotina do trabalho. 
Evidenciou-se que há uma evolução quanto à percepção de cada seção do processo tático, pois quase todas tiveram média de pontuações crescentes muito próximas, diferenciadas por casas decimais, quais foram: Obter, Utilizar e Aprender. Todas essas três pontuações ficaram poucos décimos acima uma da outra, porém todas acima de $80 \%$, o destaque levemente pior ficou com a seção contribuir, que apresentou 80,16\% dos pontos possíveis, contudo, o pior resultado. A seção que obteve melhor desempenho foi Aprender com $81,59 \%$ da pontuação possível.

No tocante ao segundo processo diagnosticado, o processo estratégico, que é composto pelas seções Avaliar, Construir/Manter e Descartar, a pontuação máxima possível era 180 pontos, e o resultado obtido ficou em 138,86 pontos, ou o equivalente a $77,14 \%$ do total. Ainda assim, pouco mais de $10 \%$ superior aos resultados encontrados por estudos com o DGC destacados por Bukowitz e Williams (2002). Este resultado demonstra que o processo estratégico está ordenado, ou organizado de maneira a funcionar adequadamente para o desenvolvimento da gestão do conhecimento no Instituto Nordeste Cidadania.

O diagnóstico do processo estratégico ainda mostrou que o melhor desempenho ficou com a seção Construir/Manter com média de 47,86 pontos dos 60 pontos possíveis, seguido da seção Avaliar que apresentou a média de 46,43 pontos, equivalente a 77,38\% do total, e o pior desempenho ficou com a seção Descartar que obteve média de 44,57 pontos. Mesmo com todas as pontuações superando o valor médio de 70\% destacado pelas autoras (2002), é importante destacar que a seção Descarte foi a que apresentou o pior resultado em todo o diagnóstico do INEC. Esse resultado demonstra que em detrimento das demais seções, na percepção dos coordenadores há uma dificuldade em descartar conhecimento, ou de não absorver o conhecimento que não é pertinente.

O aprofundamento das análises com a utilização dos 13 Indicadores de Gestão do Conhecimento elaborados por Castro (2011), destacaram que a organização ainda precisa envidar esforços no aprimorando e evidenciação de 9 itens como: processos de gestão do conhecimento, políticas de gestão do conhecimento, avaliação do conhecimento, processos decisórios, parcerias para a gestão do conhecimento, compartilhamento do conhecimento, comunicação, mensuração dos resultados, regras, dentre outros, para que os gestores intermediários (os coordenadores de unidades) possam ter um norte no que concernem as políticas, práticas, possibilidades participação e benefícios que a prática de gestão do conhecimento pode trazer no âmbito organizacional e individual, de maneira que este tipo de gestão caia na prática e na rotina das atividades diárias de cada um. 


\section{Análise das Respostas Abertas}

\subsection{Definição sobre Gestão do Conhecimento}

Para a devida análise, todas as respostas foram agrupadas dentro de um mesmo núcleo de informação, pois o software Nvivo 10 permite a organização do estudo em um banco de dados com fontes distintas para cada análise.

A figura 1, que segue, representa a análise de cluster a partir do coeficiente de correlação de Pearson (r). Ela mensura as respostas na base de dados criada a partir das perspectivas dos pesquisados no estudo quanto a pergunta feita sobre a definição do que seria a Gestão do Conhecimento, ou como eles poderiam defini-la.

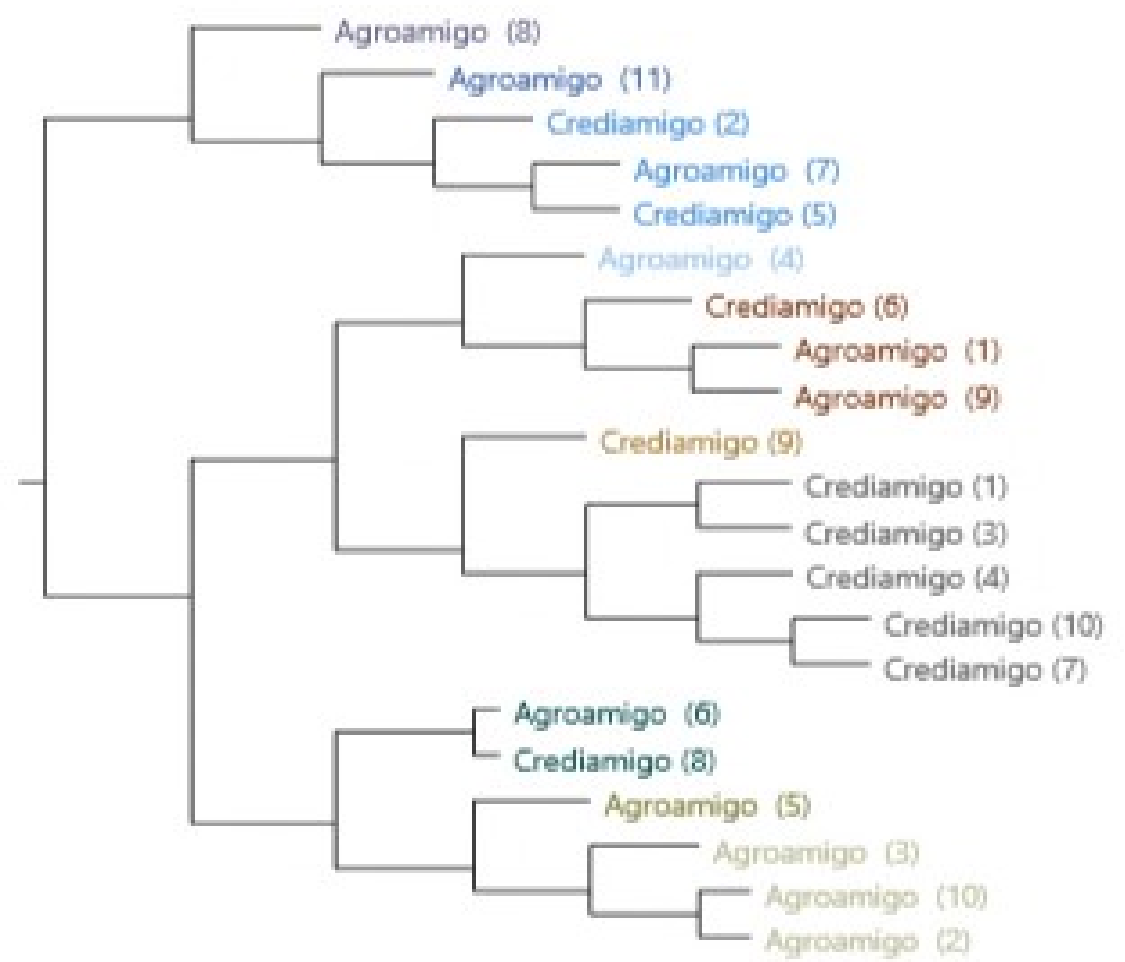

Figura 1. Análise de cluster por similaridade de palavras - Pearson $(r)$ Fonte: Dados da pesquisa, relatório extraído do programa Nvivo 10.

A figura acima foi extraída do software Nvivo 10 a partir da organização dos discursos de forma a apresentar as semelhanças no que foi dito por cada um respondente. Como pode ser visto o discurso do coordenador Agroamigo (8) é o mais diferente dos demais. Ele sugere que "gestão do conhecimento está relacionada com o capital humano que a empresa possui e a sua aplicação metodológica na facilitação do acesso as informações no ambiente organizacional". 
Os discursos de alguns dos respondentes como Crediamigo (1) e Crediamigo (3) apresentam similaridades, como também Agroamigo (1) com Agroamigo (9) e serão destacados a seguir:

"Gestão do Conhecimento é uma forma de organizar as informações de forma eficiente e distribuir para os demais colaboradores com objetivo de gerar vantagens competitivas". [Crediamigo (1)]

"Gestão do Conhecimento é como um canal de compartilhamento de informações corporativas entre os membros da equipe e outros colaboradores". [Crediamigo (3)]

"Gestão do Conhecimento é a junção e transferência de conhecimento, para que seja aplicado na empresa ou organização". [Agroamigo (1)]

"Gestão do Conhecimento é uma gestão focada na busca e gerenciamento do conhecimento". [Agroamigo (9)]

Para mensurar a similaridade dos discursos os dados obtidos na pesquisa foram tratados de maneira a comparar todas as respostas dentro do banco de dados. Na tabela 3, abaixo, a coluna Coordenadores A apresenta o discurso que teve a maior quantidade de conteúdo em texto e na coluna Coordenador B estará a resposta do seu par entrevistado e que apresentou maior similaridade, correspondente. Na terceira coluna, então, apresentamos o coeficiente de similaridades entre estas duas respostas com base no coeficiente de correlação de Pearson $(r)$. Para tanto, consideramos $(r)>0,5$, como o coeficiente mínimo aceito para apreciação dos resultados, já que há resultados que vão de 0 até 1 , ou de -1 a 0 (Dancey \& Reidy, 2006), sendo 1 uma total similaridade.

Tabela 3.

Correlação de Pearson (r) - Conhecimento sobre GC

\section{ANÁLISE SIMILARIDADE}

Coordenadores A

Agroamigo (2)

Crediamigo (7)

Crediamigo (10)

Crediamigo (5)

Crediamigo (7)

Crediamigo (7)

Agroamigo (9)

Crediamigo (7)

Crediamigo (5)
Coordenadores B

$(r)$

0,802648

0,598784

Crediamigo (10)

Crediamigo (1)

0,56968

Agroamigo (7)

0,52855

Agroamigo (7)

0,52307

Agroamigo (1)

0,522514

Agroamigo (1)

0,520201

Crediamigo (4)

0,518766

Agroamigo (9) 


$\begin{array}{lll}\text { Agroamigo (9) } & \text { Agroamigo (6) } & 0,501518 \\ \text { Crediamigo (8) } & \text { Agroamigo (9) } & 0,501518 \\ \text { Crediamigo (3) } & \text { Crediamigo (10) } & 0,500351\end{array}$

Fonte: Elaborada pelos autores com base no relatório do software Nvivo 10.

É possível verificar que existem duas respostas, o Agroamigo (2) e o Agroamigo (10) que apresentam características bem próximas, $(r)=0,802648$, o que implica alta similaridade entre estas. Para analisar o conteúdo as respostas serão expostas a seguir:

"Gestão do conhecimento é a forma que uma instituição tem de organizar estrategicamente os conhecimentos dos colaboradores e os conhecimentos externos que são relevantes para o sucesso." [Agroamigo (2)]

"Gestão do conhecimento é um processo que objetiva organizar de forma estratégica os conhecimentos dos colaboradores e os conhecimentos externos, que são fundamentais para o sucesso do negócio.” [Agroamigo (10)]

Esses coordenadores dividem um raciocínio que pode ser visto na literatura de Bukowitz e Williams (2002), pois para estas autoras uma organização que gerencia o seu conhecimento dentro de um processo elaborado em passos definidos que vai desde obtenção, utilização, aprendizagem, contribuição, dentre outros até abstenção ou descarte do conhecimento não pertinente à sustentabilidade ou futuro organizacional, poderá sobremaneira, desenvolver uma vantagem competitiva, pois é a partir da integração de como as pessoas podem aprender a partir do seu trabalho, do seu relacionamento com outros funcionários, clientes e até concorrentes que a organização cria o conhecimento organizacional com vistas a conseguir a sustentabilidade e o sucesso. 


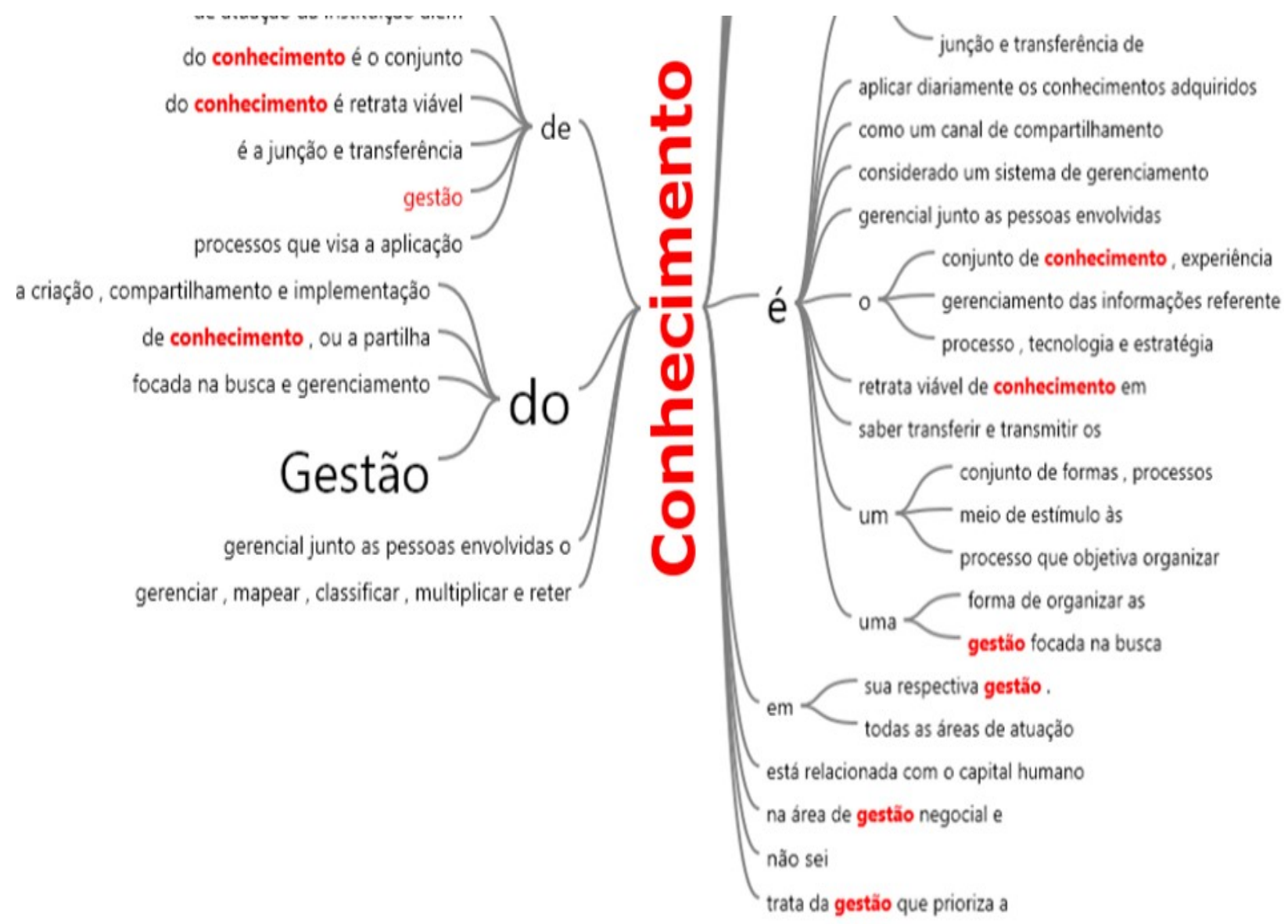

Figura 2. Definição de gestão do conhecimento pelos coordenadores de unidade

Fonte: Dados da pesquisa, adaptado a partir de relatório extraído do programa Nvivo 10.

Os resultados mostram que em diversos conteúdos de respostas há uma compreensão quanto ao que seria gestão do conhecimento no que concerne a um sistema de gerenciamento de informações e conhecimentos, um processo de gerenciamento do conhecimento, gestão do compartilhamento de conhecimento, transferência, classificação de conhecimentos, multiplicação de conhecimento dentre outros, o que mostra que os coordenadores têm ideias que podem ser encontradas em autores da área como Nonaka e Toyama (2003), Davenport e Prusak (2003), Takeuchi e Nonaka (2008) e Bukowitz e Williams (2002).

\subsection{Tipo de conhecimento compartilhado com o cliente}

Para Bukowitz e Williams (2002), é imprescindível que se tenha contato com a maior diversidade de pessoas para que seja construída uma maior variedade de conhecimentos a partir das experiências, expectativas e abordagens diferenciadas de cada pessoa perante os problemas. Para as autoras, a diversidade é um fator que habilita um aumento do potencial de respostas inovadoras e criativas a partir do conhecimento, o que pode gerar um benefício 
coletivo além de eliminar possíveis barreiras que impeçam a cooperação entre os funcionários, colegas e clientes (Takeuchi \& Nonaka, 2008; Dalkir, 2011).

Diante desta realidade, buscou-se verificar se na visão dos coordenadores havia uma percepção quanto ao tipo de conhecimento que eles transmitiam ao seu cliente. Então, nesta seção para melhor assimilação do Nvivo 10 no que compreende a análise das respostas dadas pelos coordenadores, tomou-se a liberdade de iniciar todas as respostas com o mesmo início textual (todas as respostas foram iniciadas com o texto "transmito") para que o programa pudesse ligar a resposta dada ao item que se refere e assim garantir um bom resultado para as análises seriam elaboradas.

A figura 3, abaixo, foi gerada no programa Nvivo 10 para apresentar a percepção dos coordenadores quanto ao tipo de conhecimento transmitido aos clientes que atendem. $\mathrm{O}$ programa utiliza o agrupamento de respostas quanto a uma mesma temática para expor a formação de raízes com ideias e frases que apresentam um mesmo termo ou expressão em seu contexto.

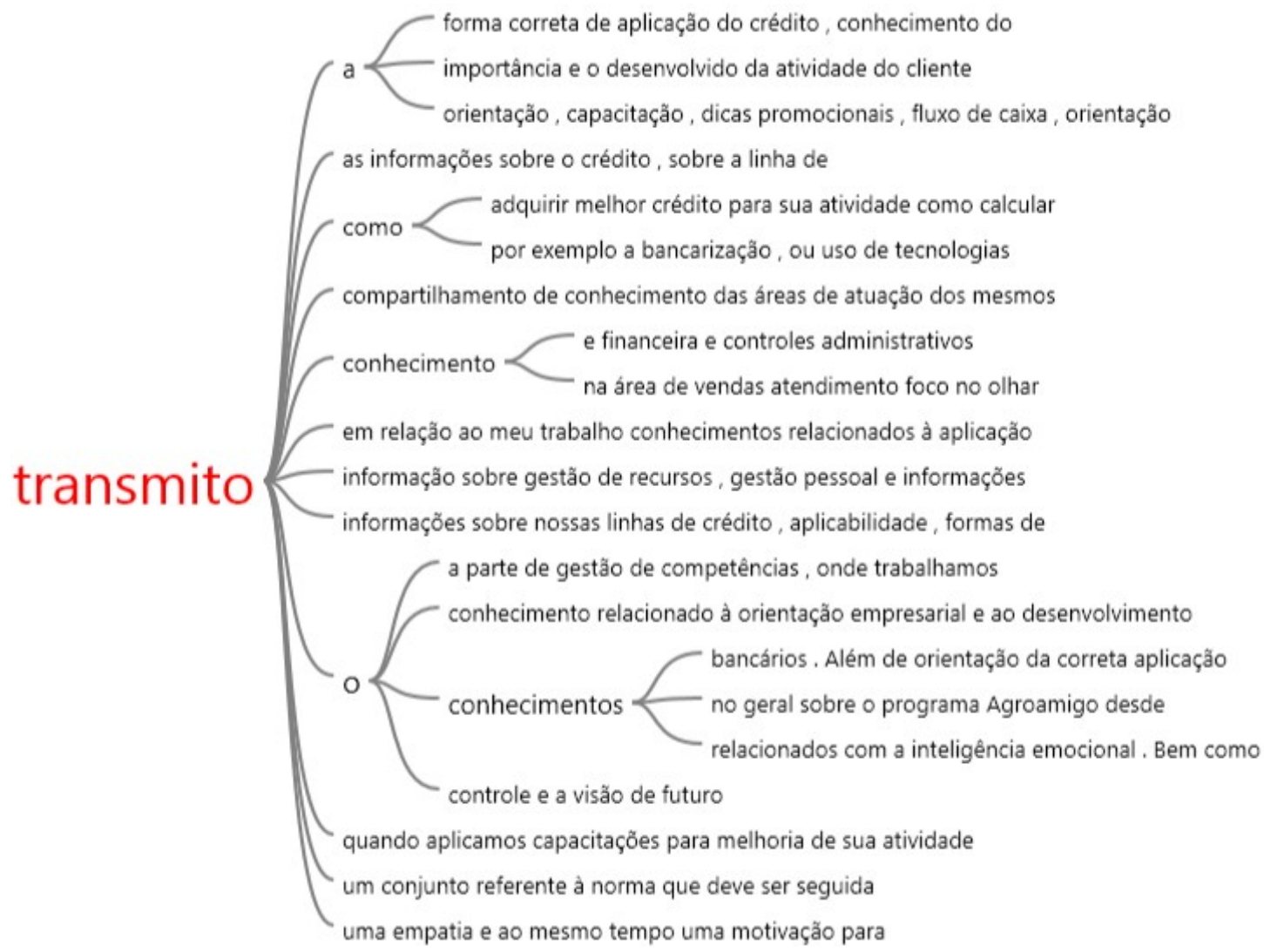

Figura 3. Tipo de conhecimento transmitido pelos coordenadores aos clientes

Fonte: Dados da pesquisa com base no relatório extraído do programa Nvivo 10.

$\mathrm{O}$ resultado do agrupamento mostra que de maneira geral os coordenadores tratam em transmitir principalmente o conhecimento pertinente aos serviços financeiros que banco

Revista de Gestão e Secretariado (GeSec), São Paulo, SP, 11(2), maio/ago., 2020, p. 75-97. 
federal parceiro da OSCIP disponibiliza, sobretudo conhecimentos quanto à tomada de crédito, bancarização, aplicação do recurso tomado no financiamento e controle financeiro. É possível notar que alguns coordenadores ainda citam que passam conhecimento sobre vendas, atendimento, sobre o uso de tecnologias e até gestão de competências, dentre outros. Ainda quanto aos resultados deste agrupamento, o software Nvivo 10 criou uma nuvem de palavras para que fosse possível visualizar os termos citados pelos coordenadores quanto ao tipo de conhecimento que transmitem para os clientes atendidos, vide figura 4.

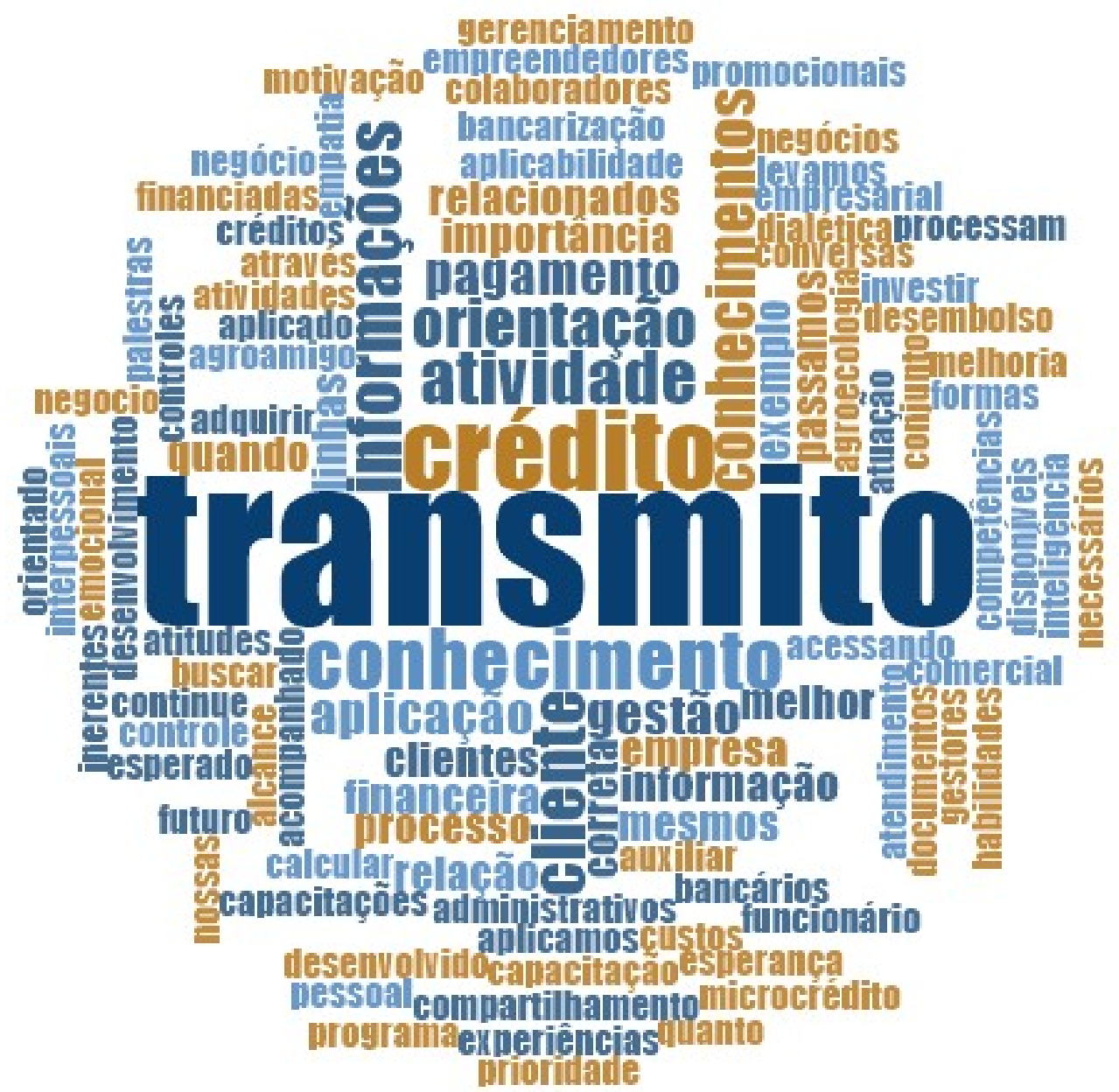

Figura 4. Nuvem com as palavras mais citadas pelos coordenadores

Fonte: Dados da pesquisa com base no relatório extraído do programa Nvivo 10.

Esta análise mostra que a nuvem de palavras corrobora com o relatório anterior, pois a lógica utilizada pelo programa para a formação desta nuvem de palavras é que quanto maior a quantidade de uma determinada palavra nas respostas analisadas, maior e mais central será a presença da palavra na formação da nuvem. Com exceção do termo "transmito" que foi inserido pelo autor do estudo em várias das respostas, merece destacar os termos: crédito(s), 
atividade, informação, conhecimento(s), orientação, pagamento, aplicação e aplicabilidade, financeira, correta, gestão, cliente dentre outras. O que confirma a compreensão de que mesmo considerando as respostas completas, os coordenadores transmitem em linhas gerais seus conhecimentos sobre o serviço bancário que é oferecido e as exigências do banco para a tomada de empréstimos e manutenção do relacionamento.

Essa análise nos mostra que precisa ser desenvolvido um direcionamento mais amplo para o compartilhamento de possíveis conhecimentos que os coordenadores tenham. Uma forma de também poder capacitar seus clientes para o desenvolvimento da atividade comercial propriamente dita, por exemplo, conhecimentos quanto a: gestão comercial ou empresarial, gestão financeira, divulgação e marketing, gestão de compras, formação de capital de giro etc. Esse compartilhamento de conhecimentos mais diversificados seria ideal para uma ampliação da variedade de conhecimentos na relação com os clientes, o que geraria um aumento no repertório de respostas aos problemas (Bukowitz \& Williams, 2002) que os clientes porventura venham a passar em suas atividades. $\mathrm{O}$ cliente de posse de uma maior variedade de conhecimento que os coordenadores pudessem transmitir geraria uma relação cuja empatia poderia eliminar as possíveis barreiras entre a cooperação (Takeuchi \& Nonaka, 2008; Dalkir, 2011).

Por fim, a análise de correlação de Pearson $(r)$ mostrou que a comparação de similaridades entre as respostas a neste item do questionário não apresentou nenhuma similaridade de resposta com pelo menos $(r)>0,5$. Na prática, não há na percepção dos coordenadores um padrão de conhecimento que seja transmitido aos clientes, cada coordenador tem uma perspectiva diferente quanto ao conhecimento que é repassado aos clientes. Convém ressaltar que o microcrédito tem como base a lei 11.110/2005 que rege a Política Nacional do Microcrédito Produtivo e Orientado, e, porventura, se não houver uma clara orientação para que os coordenadores possam se aperceber do tipo ideal de orientação que merece passar ao cliente, é possível que as normas desta lei sejam descumpridas por sua equipe. A organização necessita construir um arcabouço de conhecimentos capazes de serem levados até o cliente como forma de tornar efetivamente o microcrédito produtivo e também orientado, de maneira a desenvolver uma relação de cooperação com o cliente.

\subsection{A Gestão do Conhecimento organizacional e a influência no Nordeste}

A última pergunta feita aos coordenadores foi elaborada com a intenção de colher a percepção que os mesmos têm quanto à possibilidade do gerenciamento do conhecimento por

Revista de Gestão e Secretariado (GeSec), São Paulo, SP, 11(2), maio/ago., 2020, p. 75-97. 
parte da empresa poder influenciar no desenvolvimento do nordeste. Para tanto, todas as respostas foram agrupadas em um único bando de dados e submetidas às análises no sistema Nvivo 10 para verificar possíveis clusters capazes de mensurar a similaridade das percepções dos respondentes e apresentação dos destaques nas percepções.

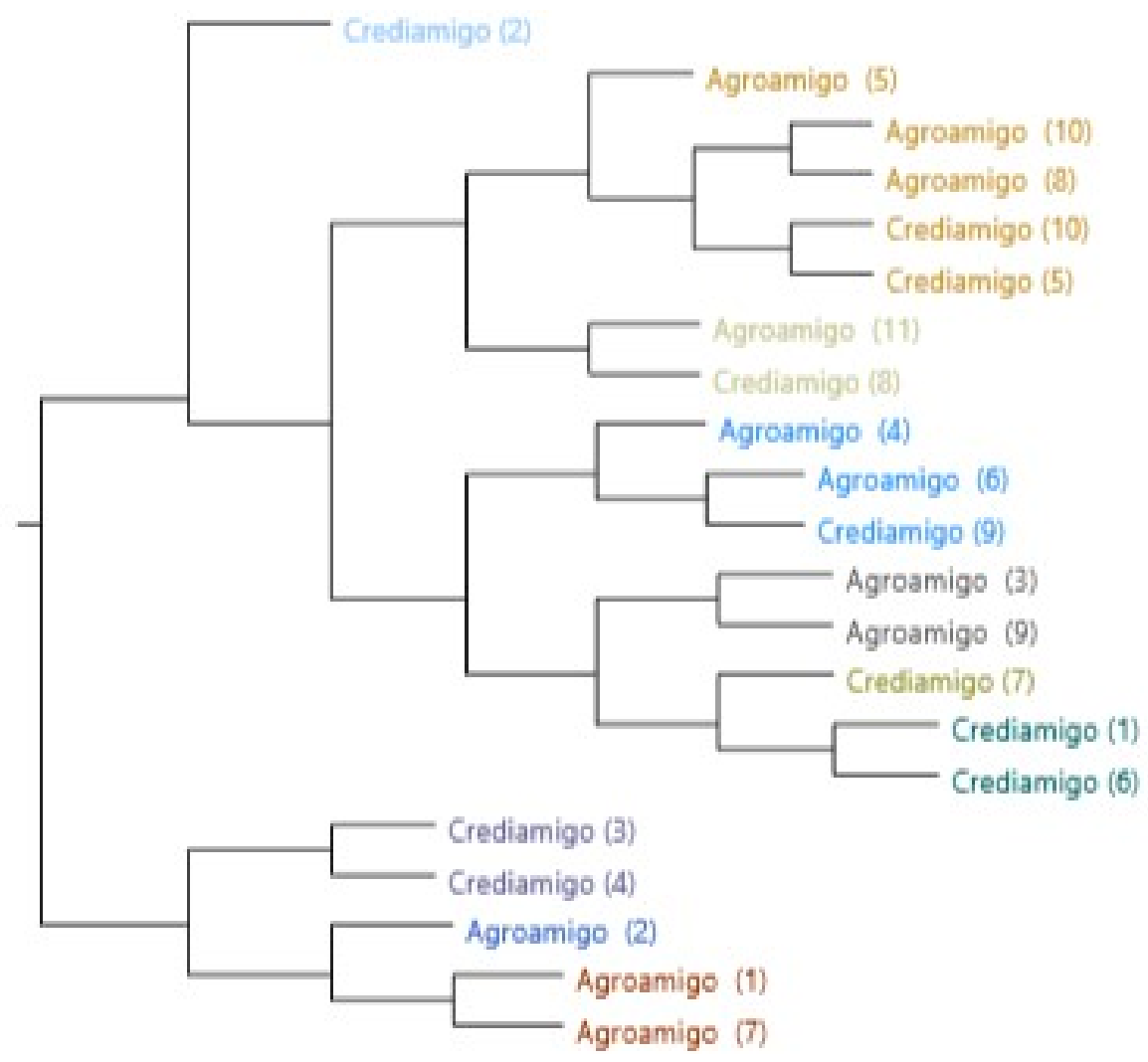

Figura 5. Análise de cluster por similaridade de palavras - Pearson ( $r$ )

Fonte: Dados da pesquisa com base no relatório extraído do programa Nvivo 10.

A figura 5, na página anterior, mostra que as respostas dos coordenadores não apresenta um conjunto preciso de similaridade. Há apenas um grupo com quatro respostas que de maneira parcimoniosa podem ser tidas como similares, são elas: Agroamigo (10) e Agroamigo (8), e os discursos Crediamigo (10) e Crediamigo (5). Para verificar o grau de similaridade, todos os discursos foram submetidos à análise por respostas aleatórias dentro do banco de dados utilizando a lógica do sistema em que na coluna A estará a resposta que tiver maior quantidade de conteúdo ou texto e na coluna B estará a sua resposta similar correspondente. A última coluna, a terceira, será a coluna $(r)$, estará preenchida com o coeficiente de correlação de Pearson $(r)$ que apresenta o grau da similaridade. A tabela 3, abaixo, apresenta os resultados com base nas respostas considerando $(r)>0,5$, que foi o coeficiente mínimo considerado para esta pesquisa, pois quanto mais próximo de 1 , maior a similaridade. 
Tabela 4.

Correlação de Pearson (r) - Influência do conhecimento no Nordeste ANÁLISE SIMILARIDADE

Coordenadores A

Agroamigo (8)

Crediamigo (5)
Coordenadores B

Agroamigo (10)

Crediamigo (10) (r)

0,521424

0,514848

Fonte: Elaboração própria com base no relatório extraído do programa Nvivo 10.

Ao considerar apenas as respostas com $(r)>5$, notadamente temos apenas dois grupos de respostas com similaridade, todas as demais respostas não atingem o padrão estabelecido para análise desta pesquisa. É sugestivo que estes quatro discursos sejam descritos para que seja possível compreender qual a percepção dos coordenadores quanto à influência do conhecimento gerido e seu impacto na região nordeste. Seguem descritas as respostas a seguir.

"Percebo na capacitação dos clientes e de todos os envolvidos com o crédito para uma melhor educação financeira e utilização e manego da atividade de forma consciente.” [Agroamigo (8)]

"Percebo com o crédito orientado e acompanhado, poderá ajudar no desenvolvimento pessoal e produtivo de cada agricultor melhorando a qualidade de vida, aumento da renda familiar e uma maior oferta de alimentos para todos nós.” [Agroamigo (10)]

"Percebo através da abertura e construção por parte dos colaboradores e clientes para discussão e aprimoramento dos conhecimentos de sustentabilidades, governança e inovação." [Crediamigo (5)]

"Percebo através do crescimento e desenvolvimento econômico e potenciais estratégicos de cada micro e macro regiões." [Crediamigo (10)]

É possível verificar que os dois coordenadores do Agroamigo têm suas percepções que o conhecimento gerenciado pelo INEC pode influenciar mediante a capacitação dos clientes no que concerne a educação financeira e crédito, o que reforça a ideia discutida na seção anterior deste trabalho (seção 4.2.2), e também pode influenciar com um conhecimento voltado ao manejo produtivo da atividade de forma consciente, orientação e acompanhamento do cliente, de maneira a ampliar a renda familiar além de uma maior oferta de alimentos para todos. Enquanto a percepção dos dois coordenadores do Crediamigo está voltada para a construção colaborativa considerando o aprimoramento dos conhecimentos de sustentabilidade, desenvolvimento econômico, estratégia, governança e inovação de cada micro e macrorregião. A figura 6 traz trechos das respostas relacionadas à percepção de todos os coordenadores a este item do questionário. 


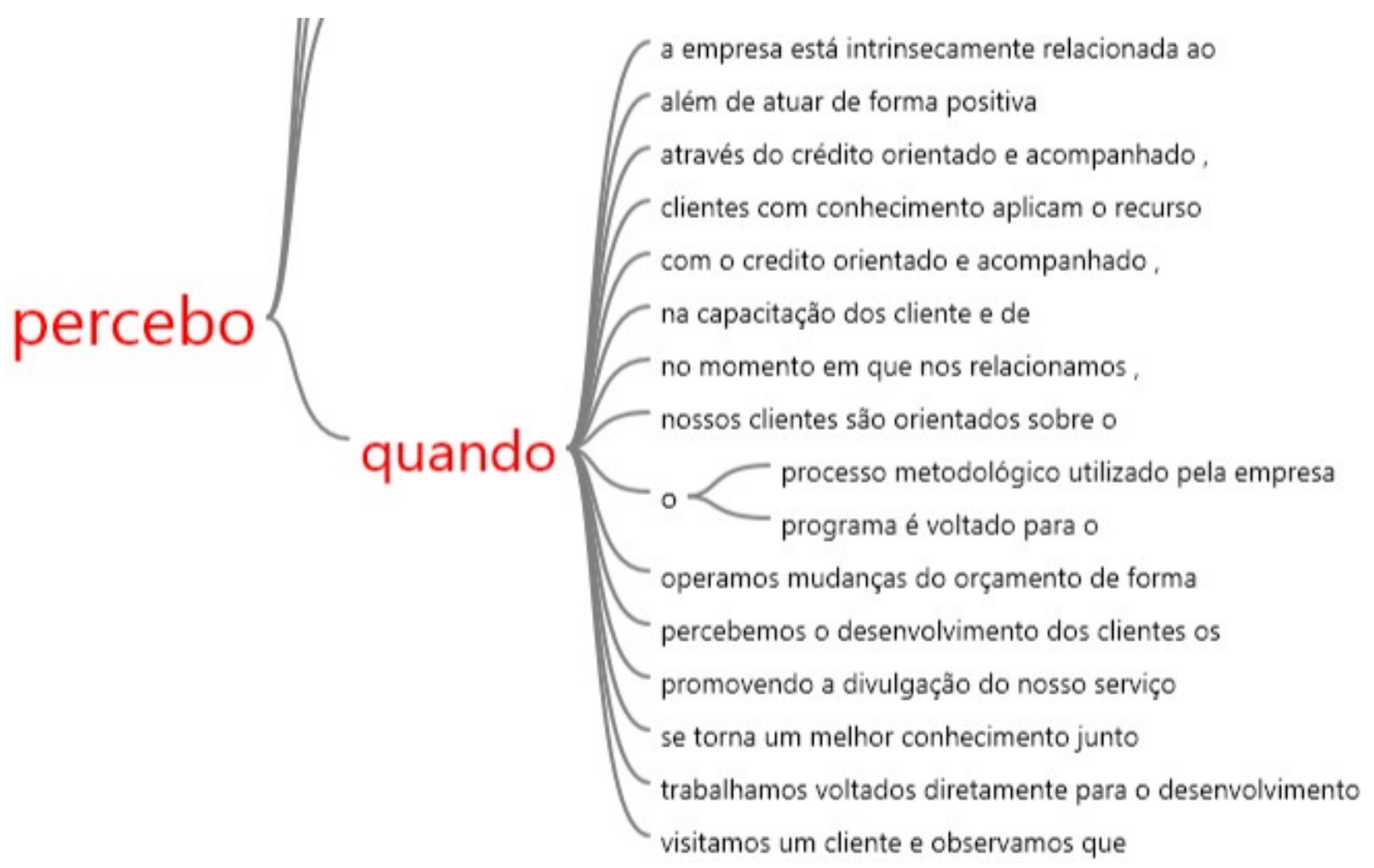

Figura 6. Percepção da influência do conhecimento na região Nordeste

Fonte: Dados da pesquisa, adaptado com base no relatório extraído do programa Nvivo 10.

É possível notar nestes trechos de respostas que as percepções dos coordenadores são variadas com ideias de crescimento e desenvolvimento econômico, orientação empresarial, crédito orientado, conhecimento quanto ao recurso aplicado, em função do relacionamento, mudança no orçamento do cliente, desenvolvimento do cliente dentre outros. A partir desta variedade de respostas se faz necessário ao INEC avaliar junto aos coordenadores as suas políticas de gestão do conhecimento no que compreende a orientação e capacitação dos clientes que são atendidos mediante a concessão de crédito para que os objetivos da empresa no que concerne a sua missão e até mesmo visão sejam lembrados, perseguidos e atingidos.

É válido reforçar que o INEC tem por missão "contribuir para a inclusão e o desenvolvimento sociocultural e econômico das pessoas, potencializando a força coletiva, promovendo a cidadania e o respeito à vida" (INEC, 2018). E também tem como visão "ser reconhecido nacionalmente até 2020, como OSCIP que promove ações de cidadania voltadas para o desenvolvimento sustentável das pessoas" (INEC, 2018). Deste modo, verifica-se que os coordenadores de alguma forma estão atuando de maneira coerente com as premissas institucionais, mas que a prática individual pode ser diferente na concessão do crédito e quanto ao repasse de conhecimentos aos seus clientes. É necessário um levantamento de tais práticas, finalidades e modus operandi de cada coordenador quanto ao repasse de conhecimento aos clientes, para não só avaliar a efetividade de cada um, mas para manter 
ávido nos coordenadores os objetivos organizacionais definidos quanto ao desenvolvimento dos dois programas de microcrédito.

\section{Considerações Finais}

A gestão do conhecimento é uma temática que visa estudar o processo do gerenciamento do ativo intangível/capital intelectual denominado conhecimento. Tem por finalidade o auxílio no desenvolvimento estratégico de formas, ferramentas, métodos e procedimentos que habilite a organização a desenvolver um arcabouço de conteúdo do conhecimento organizacional a partir de premissas como obtenção, utilização, aprendizagem, contribuição, compartilhamento, avaliação, construção, retenção do conhecimento e abstenção ou descarte do conhecimento que não é estrategicamente pertinente ao desenvolvimento e perpetuação da organização. A gestão do conhecimento tem como produto do processo a inovação e o desenvolvimento de vantagem competitiva.

A partir desta importante realidade de gestão necessária, a do conhecimento, a pesquisa é elaborada em um corte transversal para fazer um diagnóstico da gestão do conhecimento na maior OSCIP do Brasil, que é parceira de um banco federal na operacionalização de dois importantes programas de microcrédito produtivo e orientado em toda região Nordeste e norte dos estados de Minas Gerais e Espirito Santo, que tem por missão o desenvolvimento socioeconômico e cultural da população desta região atendida.

O objetivo geral deste trabalho foi diagnosticar o nível atual da gestão do conhecimento do Instituto Nordeste Cidadania, a partir da percepção dos Coordenadores de Unidades no Estado do Rio Grande do Norte, e se tornou possível pela utilização do DGC elaborados por Bukowitz e Williams (2002), de maneira que os resultados encontrados nas 7 (sete) seções do instrumento mostraram que a organização apresenta um resultado superior ao padrão encontrado pelas autoras, que é de $55 \%$, enquanto que no instituto pesquisado o resultado geral foi de 79,23\%. As análises por seção do diagnóstico mostram que a organização se manteve com todos os resultados também acima dos resultados encontrados anteriormente pelas autoras (entre 30 e 70\%), pois os resultados por seções do instituto se mantiveram acima de 70\%, com a seção Aprender se destacando com a melhor pontuação $(81,59 \%)$ e a seção Descartar com a pior pontuação (74,29\%). Estes resultados indicam que o nível de gestão do conhecimento é alto em todos os processos, com destaque para o processo tático que obteve melhores médias em detrimento do processo estratégico. 
Porém, visando um aprofundamento das análises foram utilizados os Indicadores de Gestão do Conhecimento elaborados por Castro (2011), a partir da percepção dos coordenadores quanto à utilização/ocorrência de cada uma das 140 afirmativas que formam o DGC. Os resultados destacaram que a organização ainda precisa envidar esforços no aprimorando e evidenciação de itens como processos de gestão do conhecimento, políticas de gestão do conhecimento, avaliação do conhecimento, processos decisórios, parcerias para a gestão do conhecimento, compartilhamento do conhecimento, comunicação, mensuração dos resultados, regras, dentre outros, para que os gestores intermediários (os coordenadores de unidades) possam ter um norte no que concernem as políticas, práticas, possibilidades participação e benefícios que a prática de gestão do conhecimento pode trazer no âmbito organizacional e individual, de maneira que este tipo de gestão caia na prática e na rotina das atividades diárias de cada um.

Seus objetivos específicos foram: analisar o processo tático composto pelas etapas de obtenção, utilização, aprendizagem e contribuição do conhecimento na organização, Averiguar, através do processo estratégico, como ocorre a avaliação, construção/manutenção e descarte do conhecimento na organização, e identificar a percepção dos respondentes sobre a temática gestão do conhecimento.

É válido destacar que ao cruzar os dados obtidos entre os respondentes de cada programa (Agroamigo X Crediamigo), e os respondentes com menos e mais tempo na função (com até cinco anos na função de coordenador X com mais de cinco anos na função de coordenação) ficou verificado que a menor quantidade de tempo no serviço pode ser um preditor de uma percepção mais positiva, ou com maiores chances de conceder pontuação maior para as afirmativas do diagnóstico. Tal fato foi percebido, pois o programa Agroamigo apresentou maior número de coordenadores com menos tempo na função, e, contudo, os resultados de maior e menor destaque foram similares nas seções, sobretudo quando consideradas apenas as seções do processo Tático. Por outro lado, o Crediamigo apresentou mais funcionários com mais tempo na função e, as pontuações destoaram um pouco para médias menores.

Diante dos achados desta pesquisa, é possível considerar, por fim, que o Instituto Nordeste Cidadania é uma organização que se encontra em um nível elevado de gestão do conhecimento no que se refere à captura, utilização, aprendizagem e contribuição, dentro do processo tático e avaliação, construção e descarte dentro do processo estratégico, pois todos estes passos obtiveram pontuação superior ao nível que as autoras Bukowitz e Williams (2002) têm encontrado em pesquisas elaboradas anteriormente. Outrossim, a pesquisa 
mostrou que quando considerados os indicadores de gestão do conhecimento elaborados por Castro (2011), a organização apresentou alguns pontos que ainda podem ser aprimorados para que a organização tenha uma gestão ainda mais efetiva. Este fato pode nortear quando na busca por melhorias.

Diante do material que foi aqui exposto, é positivo considerar que esta pesquisa contribuiu para que organizações do terceiro setor como Fundações, OSCIPs, ONGs, dentre outras, possam ter um material a se basear para avaliação deste bem que é tão valioso, que é o conhecimento. Mesmo diante de todo o acervo sobre Gestão do Conhecimento, poucos são os materiais que foram aplicados para apresentar a gestão do conhecimento em uma organização do terceiro setor, e se considerar efetivamente um diagnóstico, a quantidade é ainda menor, sendo impossível de encontrar em diversas bases de pesquisas.

Esta pesquisa teve como fatores limitadores a resistência dos respondentes à pesquisa, pois sinalizaram receio em serem demitidos. Outro fator que foi empecilho para recepção de mais formulários foi a quantidade de afirmativas, pois informaram que não tinham tempo para responder em função das metas que precisam atingir todo dia. Também foi notória a quantidade de formulários com alternativas em branco, que foram respondidas posteriormente mediante contato pontual com os coordenadores, o que retardou a apuração dos resultados. Por fim, alguns coordenadores preferiram não enviar a pesquisa sem sinalizar qualquer motivação para tal.

Trabalhos futuros podem ser elaborados com o objetivo de revelar se o fato de uma empresa auxiliar a fundação de outra é um fator que influencia ou evidencia a segunda empresa com pontos mais positivos para a gestão do conhecimento; ou estudos quanto à verificação se a expertise de uma empresa mais madura quando compartilhada com outra mais recente, influência de maneira positiva a gestão do conhecimento de ambas; outro fator que pode ser verificado é a percepção de gestão do conhecimento em todas as unidades do instituto na região nordeste; também será válido explorar se realmente fatores como o tempo na função é um preditor de uma percepção mais positiva de gestão do conhecimento; investigar se há diferença na percepção de gestão do conhecimento entre coordenadores de outras gerencias estaduais; ou até mesmo se a idade é um aspecto relevante na percepção de gestão do conhecimento, já que as empresas apresentaram faixas etárias distintas.

\section{Referências}

An, X., Deng, H., Chao, L., \& Bai, W. (2014). Knowledge management in supporting Revista de Gestão e Secretariado (GeSec), São Paulo, SP, 11(2), maio/ago., 2020, p. 75-97. 
collaborative innovation community capacity building. Journal of Knowledge Management, 18(3), 574-590.

Bardin, L. (2002). Análise de conteúdo. Trad. Luís Antero Reto e Augusto Pinheiro. Lisboa: Edições 70 LDA.

Bukowitz, W. R., \& Williams, R. L. (2002). Manual de Gestão do Conhecimento: ferramentas e técnicas que criam valor para a empresa. Porto Alegre: Bookman Editora.

Bukowitz, W. R., Williams, R. L., \& Mactas, E. D. (2004). Human capital mensurement. Research-technology Management, 47(3), 43-49.

Cardoso, L. (2007). Gestão do conhecimento e competitividade organizacional: um modelo estrutural. Comportamento Organizacional e Gestão, 13(2),191-211.

Castro, A. B. C. (2011). Gestão do conhecimento: um estudo em uma instituição pública de assistência técnica e extensão. Dissertação de mestrado profissional em Administração, Universidade Potiguar, Natal, RN, Brasil.

Dalkir, K. (2011). Knowledge management in theory and practice. (2a ed.). Cambridge: The MIT Press.

Dancey, C. P., \& Reidy, J. (2006). Estatística sem matemática para psicologia. Trad. Lori Viali. Porto Alegre: Artmed.

Davenport, T. H. (2015). Process Management for Knowledge Work. In: vom Brocke J., Rosemann M. (eds) Handbook on Business Process Management 1. International Handbooks on Information Systems. Springer, Berlin, Heidelberg.

Davenport, T. H., Eccles, R. G., \& Prusak, L. (1992). Information Politics. Sloan Management Review, p. 53-65.

Davenport, T. H., \& Grover, V. G. (2001). Special Issue: Knowledge Management, Journal of Management Information Systems, 18(1), 3-4.

Davenport, T. H., \& Prusak, L. (2003). Conhecimento Empresarial: como as organizações gerenciam seu capital intelectual. Rio de Janeiro: Campus.

Deng, H. (2006, November). A decision model for benchmarking knowledge management practices. In: Computational Intelligence for Modelling, Control and Automation, 2006 and International Conference on Intelligent Agents, Web Technologies and Internet Commerce, International Conference on (pp. 233-233). IEEE.

Freire, P. S.; Ueno, A. T.; Dias, M. A. H., \& Santos, N. (2013). Ferramentas de avaliação de gestão do conhecimento: um estudo bibliométrico. Int. J. Knowl. Eng. Manag., 2(3), 1638. 
Godoy, A. S. (1995). Introdução a pesquisa qualitativa e suas possibilidades. Revista de Administração de Empresas, 35(2), 57-63.

Gohn, M. G. (2004). Empoderamento e participação da comunidade em políticas sociais. Saúde e Sociedade, 13(2), 20-31.

Guerrero-Baena, M. D., Gómez-Limón, J. A., \& Fruet Cardozo, J. V. (2013). La valoración de inversiones productivas: Una aproximación metodológica basada en la creación de valor financiero e intelectual. Intangible Capital, 9(4), 1145-1169.

Gupta, U. G., Massa, N. P., \& Azzopardi, J. (2016). Culture and intelectual capital: towards a conceptual framework. International Journal of Organization Analysis, 24(3), 438-453.

Lakatos, E. M. (2003). Fundamentos de metodologia científica. (5a ed.). São Paulo: Atlas.

Nonaka, I. (1994). A dynamics theory of organizacional knowledge creation. Organization Science, 5(1), 14-37.

Nonaka, I., \& Toyama, R. (2003). The knowledge-creating theory revisited: knowledge creation as a synhesizing process. Knowledge Management Research \& Practice, 1(n), 210.

Shein, E. H. (2004). Organizational Culture and Leadership. (3rd ed.). São Francisco.CA: Jossey-Bass.

Strauhs, F. R., Pietrovski, E. F., Santos, G. D., Carvalho, H. G., Pimenta, R. B., \& Penteado, R. S. (2012). Gestão do conhecimento nas organizações. Curitiba: Aymará Educação.

Takeuchi, H., \& Nonaka, I. (2008). Gestão do conhecimento. Trad. Ana Thorell. Porto Alegre: Bookman.

Tarapanoff, K. (2006). Inteligência, informação e conhecimento em corporações. Brasília: IBICT, UNESCO.

Trompenaars, F. (1996). Resolving international conflict: culture and business strategy. London Business School, 7(3), 51-88.

Turner, J. R., Zimmerman, T., \& Allen, J. M. (2012). Teams as a sub-process for knowledge management. Journal or Knowledge Management, 16(6), 963-977.

Submetido em: 26.06.2019

Aceito em: $\quad 26.09 .2019$ 